\title{
Optimisation of in-situ dry density estimation
}

\author{
Mathilde Morvan ${ }^{1, a}$ and Pierre Breul ${ }^{1}$ \\ ${ }^{1}$ Institut Pascal, Université Blaise Pascal, Clermont-Ferrand, France
}

\begin{abstract}
Nowadays, field experiments are mostly used to determine the resistance and settlements of a soil before building. The needed devices were heavy so they cannot be used in every situation. It is the reason why Gourves et al (1998) developed a light dynamic penetrometer called Panda. For this penetrometer, a standardized hammer has to be blown on the head of the piston. For each blow, it measures the driving energy as well as the driving depth of the cone into the soil. The obtained penetrogram gives us the cone resistance variation with depth. For homogeneous soils, three parameters can determined: the critical depth $z_{c}$, the initial cone resistance $q_{d 0}$ and the cone resistance in depth $q_{d l}$. In parallel to the improvement of this apparatus, some researches were lead to obtain a relationship between the dry density of soil and the cone resistance in depth $q_{d l}$. Knowing dry density of soil can allow to evaluate compaction efficiency for example. To achieve this point, a database of soils was initiated. Each of these soils was tested and classified using laboratory tests, among others, grain size distribution, proctor results, Atterberg limits. Penetrometer tests were also performed for three to five densities and for three to five water contents. Using this database, Chaigneau managed to obtain a logarithmic relation linking $q_{d l}$ and dry density. But this relation varies with the water content. This article presents our recent researches on a mean to obtain a unified relation using water content, saturation degree or suction. To achieve this point, at first we studied the CNR silt responses with saturation degree and water content. Its water retention curve was realised using filter paper method so we can obtain suction. Then we verified the conclusion of this study to seven soils of the database to validate our hypotheses.
\end{abstract}

\section{Introduction}

Panda penetrometer is a light dynamic penetrometer that allows to obtain soil cone resistance for first soil meters.

Previous researches showed that a relationship between dry density of tested materials and cone resistance exists. For Panda [1, 2, 3], this unique relationship was enlightened for a given soil and a given water content. Five water contents were studied depending on proctor optimum: very dry, dry, medium, wet, very wet. The aim of this paper is to propose a new relationship valid for any water content in order to reduce uncertainty of the in-situ dry density evaluation. Moreover climatic changes push researcher to study the bearing capacity variation due to drying-wetting cycles. This new relationship will allow to have a new evaluation of bearing capacity after a change of water content. In the future, this evaluation could give us a mean to evaluate suction in-situ using other parameters that can be easily obtained in laboratory (for example: grain size distribution, proctor results, Atterberg limits).

\section{Panda and data base}

Panda is a light dynamic penetrometer using variable energy. Due to its small size (cone of $4 \mathrm{~cm}^{2}$ and rods diameter of $15,4 \mathrm{~mm}$ ) and its lightness, it gives the opportunity to examine first meters of most soft soils even when it is hard to get to.

The dynamic beating is realized manually by the mean of a standardized hammer. The beating energy and the cone displacement are recorded for each blow. Thanks to this simultaneous measurement, the device provides a penetrogram (cone resistance variation versus depth) with a cone resistance measurement every each 5 $\mathrm{mm}$ of cone displacement on average (Fig.1).

From the recorded penetrogram, several parameters are deduced for homogenous soil [1]:

- Critical depth $z_{c}$, depth from which cone resistance stays constant

- Initial cone resistance $q_{d 0}$

- Average cone resistance below $z_{c}, q_{d 1}$.

Like all penetrometers, Panda device has been developed in order to obtain the in situ mechanical soil properties during geotechnical soil investigations. But considering that the dynamic resistance of a soil is strongly connected to the state of density of the tested

\footnotetext{
${ }^{a}$ Corresponding author: mathilde.morvan@univ-bpclermont.fr
} 
materials it can also be used for the control of compaction [4], as for example in the control of tailing deposits in Chile [5].

In order to obtain an indirect evaluation of the dry density of the studied soil, relations linking the cone resistance in depth $\left(q_{d l}\right)$ measured with the Panda to the material dry density were established. For that purpose, a base of "model soils" (containing 1 to 3 materials for each class of soils defined in the French classification (GTR)) was built [6]. The objective of this base of "model soils" is to be able to characterize any soil studied in situ by referring to "model soils" of similar properties. For each material, Panda tests have been carried out in a calibration chamber $(80.6 \mathrm{~cm}$ height and diameter of 37.5 $\mathrm{cm}$ ), for five levels of density, varying from the bulk density to about $110 \%$ of the standard Proctor density and for three different water content corresponding to a wet, medium, and dry state.

Chaigneau [4] showed that for one material class at given water content, the relation linking the cone resistance to the dry density was:

$$
\gamma_{d}=\alpha \ln \left(q_{d 1}\right)+\beta
$$

This relation being valid for one water content, it would be interesting to be able to generalize it for all ranges of water content of a soil in order to estimate the in situ dry density of a material only from the knowledge of the geotechnical soil classification and from a penetrometric test.

We thus undertook to study the influence of the water content on this relation and on the soil parameters.

\section{Study of CNR silt}

In our database, we can find silt named CNR silt and classified in A1-2 for the French GTR classification. Its characteristics are:

- D $\max =2.6 \mathrm{~mm}$

- Passing at 80 microns: $77.76 \%$

- Grain volumetric weight: $26.62 \mathrm{kN} / \mathrm{m}^{3}$.

- Liquidity limit: $25.8 \%$

- Plasticity limit: $22.5 \%$

- Normal proctor results: wopt $=14.2 \%$ and optimum dry volumetric weight $17.98 \mathrm{kN} / \mathrm{m} 3$

This database also gives us results of dynamic penetrometer Panda tests for each soil at different hygrometry and density. For each test, average dry density, cone resistance in depth and average water content are measured. Each test is repeated three times, presented results are the average of these three tests. Figure 1 presents an example of the obtained penetrogram for wet CNR silt. Thanks to this penetrogram we obtained $z_{c}=0.26 \mathrm{~m}, q_{d l}=4.05 \mathrm{MPa}$, $q_{d 0}=2.33 \mathrm{MPa}$. In this study, only $q_{d l}$, the cone resistance in depth, will be used.

The objective of the presented study was to characterize the influence of pore water on cone resistance.

In order to verify water content effects on cone resistance, we present results in $\left(q_{d l}, \gamma_{d}\right)$ plane without taking water content variations into account (Fig 2). We can notice that the obtained relationship is not accurate enough and the dependency to water content is to be studied.

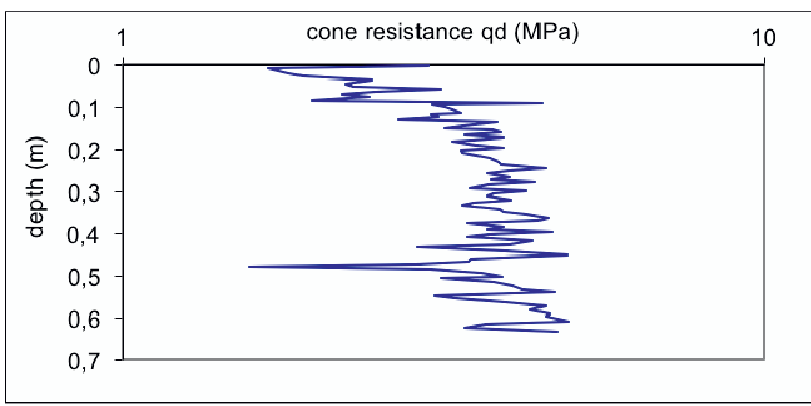

Figure 1: example of CNR silt penetrogram

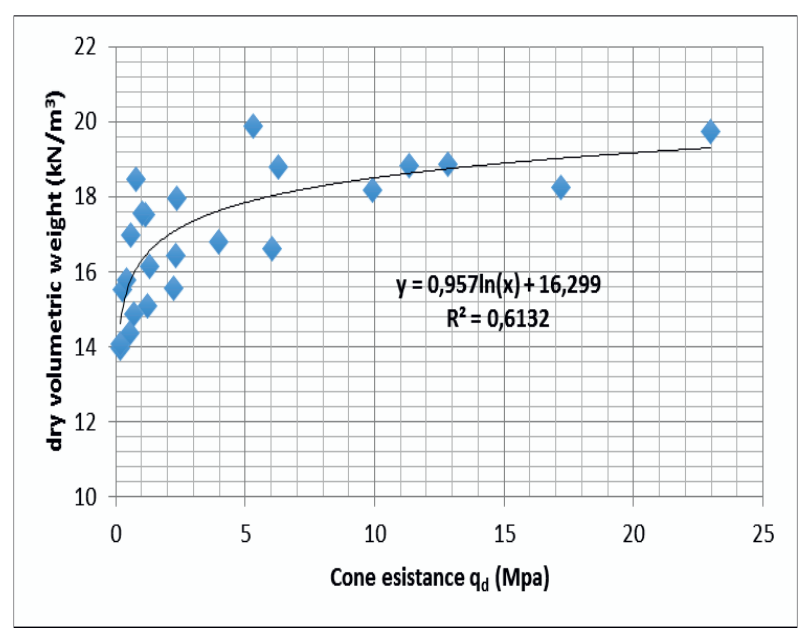

Figure 2: Calibration points ( $q_{d l}$ vs $\left.\gamma_{d}\right)$ plotted together without water content distinction

Calibration curves for each water content tested are presented in fig 3 . With these calibration curves, knowing water content of a soil, we can approximate a $\gamma_{d}=f\left(q_{d 1}\right)$ law. No generalized law has been found yet. This is what we will study in this article.

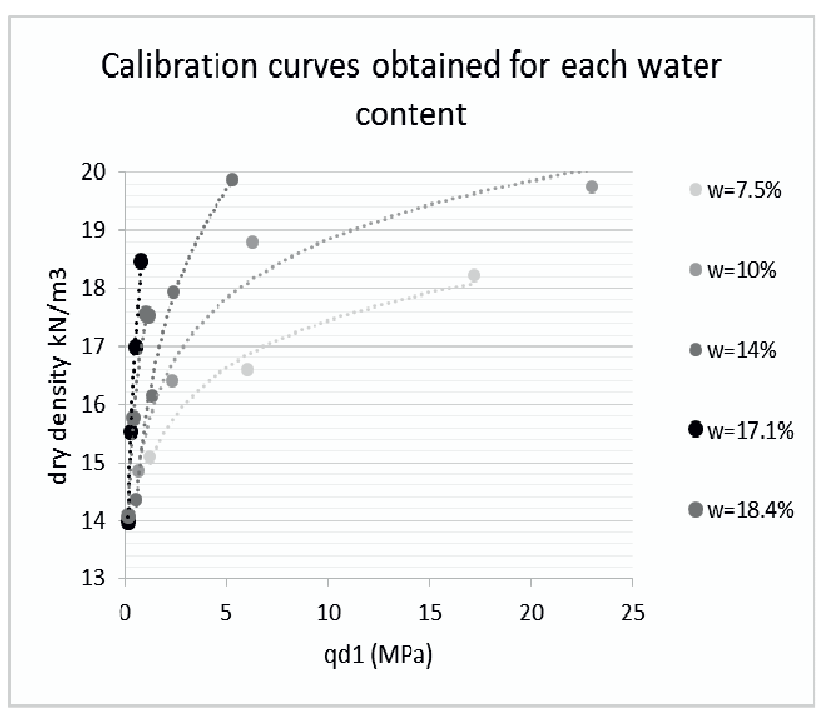

Figure 3: Calibration curves ( $q_{d l}$ vs $\gamma_{d}$ ) for different water contents. 
These curves lead to the following relationship for each water contents:

$$
\gamma_{d}=\alpha(w) \ln \left(q_{d 1}\right)+\beta(w)
$$

Table 1: variation of $\alpha$ and $\beta$ parameters with water content

\begin{tabular}{|r|r|r|}
\hline $\mathrm{w}(\%)$ & $\alpha\left(\mathrm{kN} / \mathrm{m}^{3}\right)$ & $\beta\left(\mathrm{kN} / \mathrm{m}^{3}\right)$ \\
\hline 7,5 & 1,1714 & 14,748 \\
\hline 10,0 & 1,4646 & 15,468 \\
\hline 13,1 & 1,8637 & 14,113 \\
\hline 14,0 & 2,4699 & 15,721 \\
\hline 17,1 & 2,7297 & 18,896 \\
\hline 18,4 & 1,9625 & 17,413 \\
\hline
\end{tabular}

Table 1 summarizes obtained parameters. Fig 4 shows values of $\alpha$ and $\beta$ parameters versus water content. It is difficult to conclude on the dependency of these parameters on water content. Any correlation cannot be found. So we decided to study another variable.

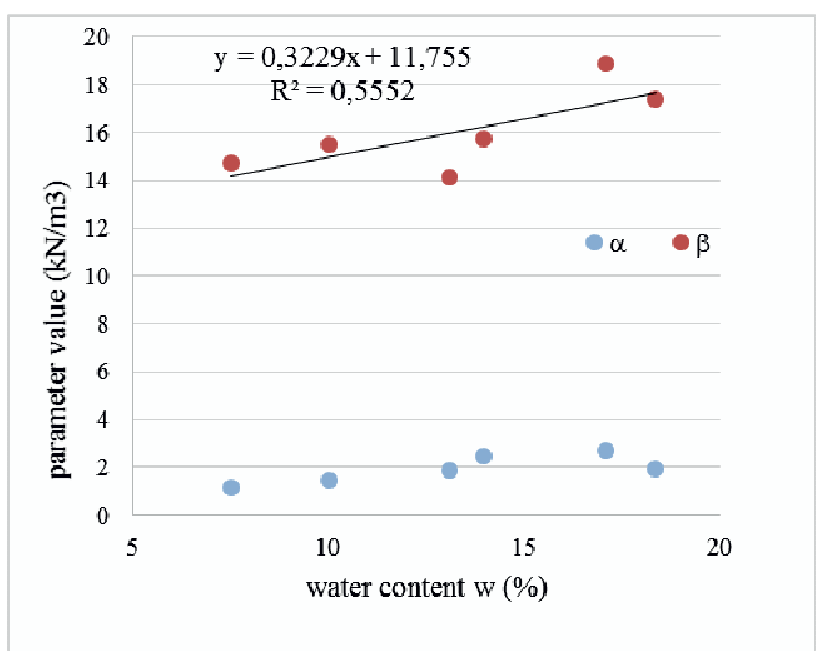

Figure 4: variation of $\alpha$ and $\beta$ parameters with water content

To describe the mechanical behaviour of unsaturated soils, water content is not usually taken to represent pore water but instead it is saturation degree Sr. Sr can be obtained using water content and dry density:

$$
S_{r}=\frac{w}{\frac{\gamma_{w}}{\gamma_{d}}-\frac{\gamma_{w}}{\gamma_{s}}}
$$

So we chose to study the $\gamma_{d}=f\left(q_{d 1}\right)$ relationship with saturation degree (Fig. 5). This new relationship can be written in the following form:

$$
\gamma_{d}=A\left(S_{r}\right) \ln \left(q_{d 1}\right)+B\left(S_{r}\right)
$$

Results of $\mathrm{A}$ and $\mathrm{B}$ for different saturation degrees are presented in table 2 and plotted in Fig 6.

Variation of A with $S_{r}$ is not obvious but we observed a logarithmic type relationship between B and $S_{r}$.

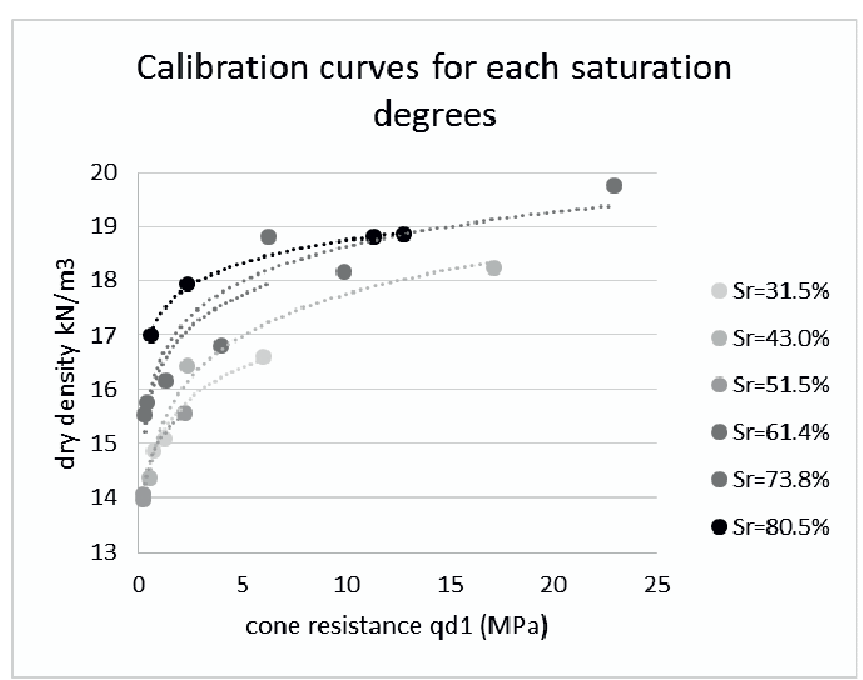

Figure 5: Calibration curves ( $q_{d l}$ vs $\left.\gamma_{d}\right)$ for different saturation degrees

Table 2: variation of $\mathrm{A}$ and $\mathrm{B}$ with $\mathrm{Sr}$

\begin{tabular}{|r|r|r|}
\hline $\mathrm{A}\left(\mathrm{kN} / \mathrm{m}^{3}\right)$ & $\mathrm{B}\left(\mathrm{kN} / \mathrm{m}^{3}\right)$ & $\mathrm{Sr}(\%)$ \\
\hline 0,83 & 15,07 & 31,57 \\
\hline 1,11 & 15,19 & 42,98 \\
\hline 0,61 & 15,07 & 51,46 \\
\hline 0,87 & 16,35 & 61,43 \\
\hline 0,92 & 16,52 & 73,86 \\
\hline 0,59 & 17,37 & 80,47 \\
\hline
\end{tabular}

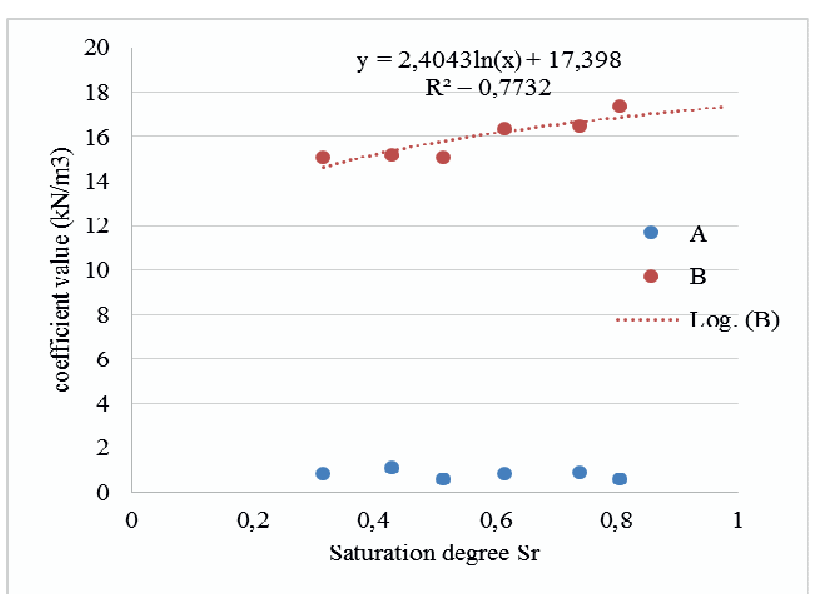

Figure 6: variation of $\mathrm{A}$ and $\mathrm{B}$ with $\mathrm{Sr}$

Fig 6 shows a logarithmic relationship between B and saturation degree $S_{r}$. We considered that A remains constant. So we proposed a new relationship:

$$
\gamma_{d}=A \ln \left(q_{d 1}\right)+B^{\prime}+C^{\prime}\left(S_{r}\right)
$$

Before going further in applying this new formula to the database soils, we wanted to validate our results using other researchers' studies. 


\section{First step to validate the obtained relationship}

Among previous studies on cone resistance, Pournaghiazar, M., Russell, A. R. \& Khalili, N. [7, 8] formulated a relationship for CPT. This relation is given in eq. 6 .

$$
q_{c}=A p^{B} e^{C D_{r}}
$$

With p' confining effective stress and $\mathrm{D}_{\mathrm{r}}$, relative density $\left(D_{r}=\frac{e_{\max }-e}{e_{\max }-e_{\min }}\right)$.

We can rewrite this equation to get closed to the previously proposed relationship:

$$
\gamma_{d}=A^{\prime \prime} \ln \left(q_{d 1}\right)+B^{\prime \prime}+C^{\prime \prime}\left(p^{\prime}\right)
$$

If we consider the simplified form of effective stress given by Bishop:

$$
\sigma^{\prime}=\sigma-u_{a}+s S_{r} \quad \text { so } p^{\prime}=p-u_{a}+s S_{r}
$$

We made the assumption that calibration curves were realized with no confining pressure and that air pore pressure is zero. So eq5 can be simplified and gives:

$$
\gamma_{d}=A^{\prime \prime} \ln \left(q_{d 1}\right)+B^{\prime \prime}+C^{\prime \prime}\left(s S_{r}\right)
$$

To verify this equation, we measured the retention curve of CNR silt. This curve gives suction for each saturation degree. To obtain this curve we used the filter paper technique $[9,10,11]$. Normalised Whatman 42 filter papers were used. For each point, water content and void ratio of the soil were measured as well as the water content of the filter paper. This method is based on the suction equilibrium between the sample and the filter paper with a well-known retention curve. Suction of the filter paper can be obtained using these equations:

$$
\begin{aligned}
& \text { For } w<45.3 \% \\
& \log (s)=5.327-0.0779 w \\
& \text { For } w>45.3 \% \\
& \log (s)=2.412-0.0135 w
\end{aligned}
$$

To verify the obtained results, a simulation was performed using a model developed by Aubertin et al [12]. This simulation, mainly based on grain size distribution, is compared to our experimental results in Fig. 7)

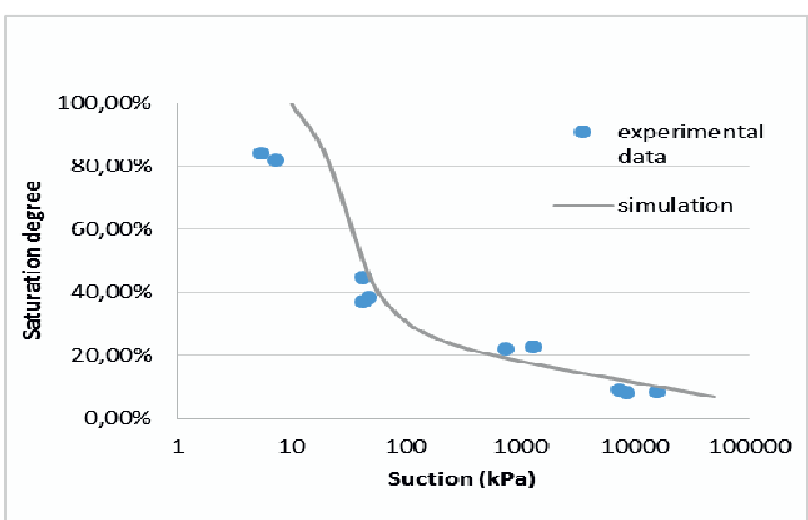

Figure 7: water retention curve of CNR silt

Samples where realised at a constant void ratio of 0.80. Fig. 8 shows the experimental points obtained and the simulation results using a Brooks and Corey law (12).

$$
S_{r}=\left(\frac{s_{e}}{s}\right)^{k}
$$

Where $s_{e}$, air entry suction and $k$ are material parameters linked to particle size distribution and particle chemistry.

For CNR silt, we obtained se $=5 \mathrm{kPa}$ and $\mathrm{k}=0.25$.

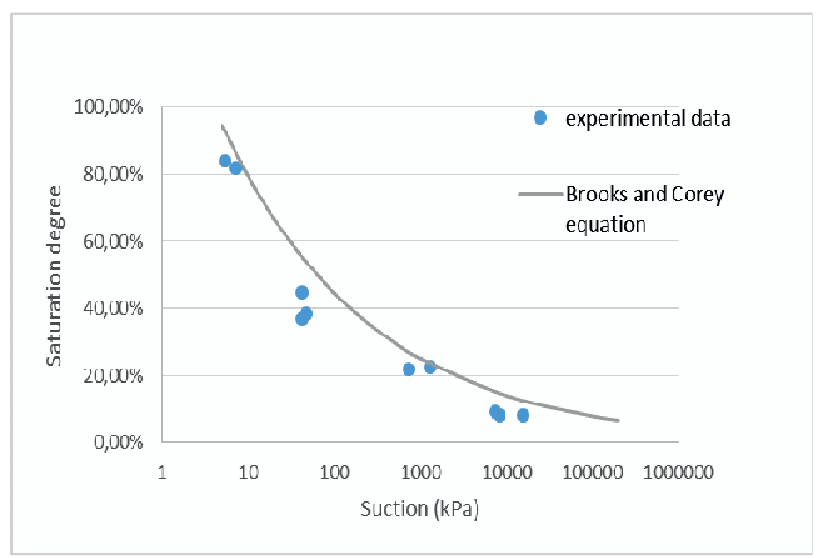

Figure 8: water retention curve of CNR silt

Fig 9 and Table 3 show the dependency of B parameter toward $s S_{r}$.

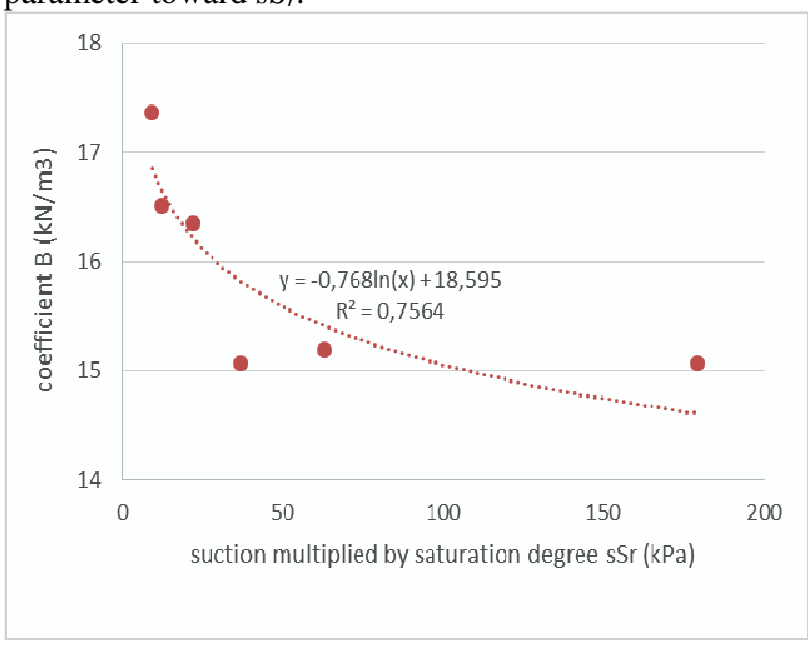

Figure 9: variation of and $\mathrm{B}$ with $\mathrm{sSr}$ 
Table 3: variation of $\mathrm{A}$ and $\mathrm{B}$ with suction and $\mathrm{sSr}$

\begin{tabular}{|c|c|c|c|}
\hline A & B & Succion $(\mathrm{kPa})$ & $\mathrm{sSr}(\mathrm{kPa})$ \\
\hline 0,83 & 15,07 & 567,73 & 179,23 \\
\hline 1,11 & 15,19 & 147,12 & 63,23 \\
\hline 0,61 & 15,07 & 72,14 & 37,13 \\
\hline 0,87 & 16,35 & 35,76 & 21,97 \\
\hline 0,92 & 16,52 & 16,97 & 12,54 \\
\hline 0,59 & 17,37 & 12,01 & 9,67 \\
\hline
\end{tabular}

The obtained curve global equation is:

$$
\gamma_{d}=0.82 \ln \left(q_{d 1}\right)+18.595-0.768\left(s S_{r}\right)
$$

Using Brooks and Corey equation (eq.12), we get:

$$
\gamma_{d}=A^{\prime \prime} \ln \left(q_{d 1}\right)+B^{\prime \prime}+C^{\prime \prime} \ln \left(s_{e} S_{r} \frac{-1}{k}\right)+C^{\prime \prime} \ln \left(S_{r}\right)
$$

That can be expanded:

$$
\gamma_{d}=A^{\prime \prime} \ln \left(q_{d 1}\right)+B^{\prime \prime}+C^{\prime \prime} \ln \left(s_{e}\right)-\frac{C^{\prime \prime}}{k} \ln \left(S_{r}\right)+C^{\prime \prime} \ln \left(S_{r}\right)
$$

If we simplify the previous equation:

$$
\gamma_{d}=A \ln \left(q_{d}\right)+B^{\prime}+C^{\prime} \ln \left(S_{r}\right)
$$

With $\mathrm{A}^{\prime}=\mathrm{A}^{\prime \prime} ; \mathrm{B}^{\prime}=\mathrm{B}^{\prime \prime}+\mathrm{C}^{\prime \prime} \ln \left(\mathrm{s}_{\mathrm{e}}\right) ; C^{\prime}=C^{\prime \prime}\left(1-\frac{1}{k}\right)$

Equation (16) has the same form as equation (5). The proposed equation is in agreement with bibliography. In order to verify this equation on other kind of soils, we performed a global study on seven soils of our database. For CNR, using obtained B', and C', with retention curve parameters, we get $B^{\prime}=17.48$ and $C^{\prime}=2.4$. These values are close from those obtained from the best fit regression.

\section{Results obtained on seven soils}

We chose in our previously presented database different kinds of soils: sands, silts and clays. Among them, we chose three sands: Sayat sand, Sermentison sand and Hauterverne sand. For silts, we selected two: CNR silt and DGA silt. Lachamps and Allier clays were used in this study. Their characteristics are summarized in Table 4 and Table 5.

Table 4: Sands characteristics

\begin{tabular}{|l|l|l|l|}
\hline Soil & $\begin{array}{l}\text { Sayat } \\
\text { sand }\end{array}$ & $\begin{array}{l}\text { Hauteverne } \\
\text { sand }\end{array}$ & $\begin{array}{l}\text { Sermentison } \\
\text { sand }\end{array}$ \\
\hline $\mathrm{D}_{\max }(\mathrm{mm})$ & 2.5 & 8 & 6 \\
\hline $\begin{array}{l}\text { Passing at } \\
2 \mathrm{~mm}(\%)\end{array}$ & 90.5 & $>70$ & 62.5 \\
\hline $\begin{array}{l}\text { Passing at } \\
80 \mathrm{microns} \\
(\%)\end{array}$ & 4.9 & 37.29 & 12.90 \\
\hline $\mathrm{w}_{\mathrm{l}}(\%)$ & 22.4 & - & 26.2 \\
\hline $\mathrm{w}_{\mathrm{p}}(\%)$ & 17.9 & - & - \\
\hline $\mathrm{Classification}$ & $\mathrm{B} 2-1$ & $\mathrm{~A} 1-3$ & $\mathrm{~B} 5-2$ \\
\hline $\mathrm{w}_{\mathrm{opt}}(\%)$ & 11 & 13.9 & 11.1 \\
\hline$\gamma_{\mathrm{opt}}\left(\mathrm{kN} / \mathrm{m}^{3}\right)$ & 19.30 & 18.57 & 19.76 \\
\hline
\end{tabular}

Table 5: Silts and clays characteristics

\begin{tabular}{|l|l|l|l|l|}
\hline Soil & $\begin{array}{l}\text { CNR } \\
\text { silt }\end{array}$ & $\begin{array}{l}\text { DGA } \\
\text { silt }\end{array}$ & $\begin{array}{l}\text { Lachamps } \\
\text { clay }\end{array}$ & $\begin{array}{l}\text { Allier } \\
\text { clay }\end{array}$ \\
\hline $\mathrm{D}_{\max }(\mathrm{mm})$ & 0.26 & 0.37 & 0.08 & 0.71 \\
\hline $\begin{array}{l}\text { Passing at } \\
2 \mathrm{~mm}(\%)\end{array}$ & 99.8 & 98.5 & 99.3 & 99.5 \\
\hline $\begin{array}{l}\text { Passing at } \\
80 \text { microns } \\
(\%)\end{array}$ & 77.76 & 91.3 & 96.73 & 67.9 \\
\hline $\mathrm{w}_{1}(\%)$ & 25.8 & 27.9 & 42.7 & 36.1 \\
\hline $\mathrm{w}_{\mathrm{p}}(\%)$ & 22.5 & 22.9 & 27.6 & 23.2 \\
\hline Class & $\mathrm{A} 1-2$ & $\mathrm{~A} 1-1$ & $\mathrm{~A} 2-1$ & $\mathrm{~A} 2-2$ \\
\hline $\mathrm{w}_{\mathrm{opt}}(\%)$ & 14.2 & 13.3 & 15.8 & 14.9 \\
\hline$\gamma_{\mathrm{opt}}\left(\mathrm{kN} / \mathrm{m}^{3}\right)$ & 17.98 & 18.35 & 18.08 & 17.60 \\
\hline
\end{tabular}

This study is based on more than 250 tests performed with the dynamic penetrometer PANDA in our calibration chamber.

Results of the three parameters A', B', C' calculated for each soil are given in Table 6.

These parameters are close for both CNR and DGA silts as well as for both Lachamps and Allier clay. Classification of these two silts is A1 and for these two clays A2. It seems that coefficients are close for soils of the same characteristics. These three selected sands do not have the same classification and we can notice that the observed parameters varies a lot for parameter C'.

Table 6: Obtained parameters for 7 studied soils

\begin{tabular}{|l|r|r|r|l|}
\hline & \multicolumn{1}{|l|}{ A' } & \multicolumn{1}{l|}{ B' } & \multicolumn{1}{l|}{ C' $^{\prime}$} & class \\
\hline Sayat sand & 0,65 & 17,52 & 1,41 & B2-1 \\
\hline Hauteverne sand & 0,67 & 18,76 & 4,26 & A1-3 \\
\hline Sermentison sand & 1,04 & 18,85 & 3,56 & B5-2 \\
\hline CNR silt & 0,82 & 17,40 & 2,40 & A1-2 \\
\hline DGA silt & 1,22 & 16,78 & 2,32 & A1-1 \\
\hline Lachamps clay & 1,06 & 16,59 & 5,33 & A2-1 \\
\hline Allier clay & 1,29 & 15,56 & 4,25 & A2-2 \\
\hline
\end{tabular}

It is very uneasy to compare the previously used method using approximated calibration curves and our three parameters law.

Table 7 presents the precision of dry density calculated with the previously developed law (eq. 2) and our three parameters law (eq. 5).

We can notice that the new relationship improves the average difference by a factor two and the maximum difference by about three. This first improvement is significant. Moreover, the three parameters needed could be kept constant for the same type of soil. This hypothesis has to be verified for sand but it seems verified for A1 silts and A2 clays. 
Table 7: Improvement due to new relationship

\begin{tabular}{|l|l|l|}
\hline & $\begin{array}{l}\text { Previous } \\
\text { method }\end{array}$ & $\begin{array}{l}\text { Three } \\
\text { parameters } \\
\text { law }\end{array}$ \\
\hline $\begin{array}{l}\text { RMS between } \\
\text { measured } \gamma_{d} \text { and } \\
\text { calculated } \gamma_{d}\end{array}$ & $1.03 \mathrm{kN} / \mathrm{m}^{3}$ & $0.48 \mathrm{kN} / \mathrm{m}^{3}$ \\
\hline $\left.\begin{array}{l}\text { Maximum } \\
\text { difference between } \\
\text { measured } \gamma_{d} \text { and } \\
\text { calculated } \\
\left(\mathrm{kN} / \mathrm{m}^{3}-\%\right)\end{array} \quad \begin{array}{l}3,00 \mathrm{kN} / \mathrm{m}^{3}- \\
\hline \begin{array}{l}\text { Average difference } \\
\text { between measured } \\
\gamma_{d} \text { and calculated } \gamma_{d} \\
(\mathrm{kN} / \mathrm{m} 3-\%)\end{array}\end{array}\right) \begin{array}{l}1.23 \mathrm{kN} / \mathrm{m}^{3}- \\
8.69 \%\end{array}$ \\
\hline
\end{tabular}

\section{Conclusion}

To conclude with, we proposed a new $\gamma_{d}=f\left(q_{d 1}\right)$ relationship. This law used with the variable energy panda penetrometer to estimate dry density is closed to the one used on CPT [8]. This law was verified on different kind of soils. Parameters seem to be constant for each kind of soils regarding the French GTR classification. So these parameters depend on grain size distribution, Atterberg limits and proctor results. With this new relationship it is now possible to evaluate accurately dry density of soils. And in our climate changes context, it can also be used to predict cone resistance variation with hydrometric changes in soils. So it can lead to more sustainable road designs.

\section{References}

1. Gourvès R., Richard B., Le pénétromètre dynamique léger PANDA, Proceeding of ECSMFE, Copenhagen, Denmark, pp 83-88, (1995).

2. R. Gourvès, F. Oudjehane et S. Zhou, The in-situ characterization of mechanical properties of granular media with the help of penetrometers, proceeding of Powders and Grains, Durham, USA, pp. 57-60 (1997)

3. Breul, P.; Benz, M.; Gourvès, R. and Saussine, G. Penetration test modelling in a coarse granular medium. International conference on micromechanics of granular media, Powder and Grain, AIP Conf. Proc., Golden, Colorado, USA vol 1145, pp. 173-176 (2009).

4. Chaigneau, L., Gourvès, R., Bacconnet, C., Penetration test coupled with a geotechnical classification for compaction control, GeoEng2000 An international conférence on geotechnical \& geological Engineering, Melbourne, Australia, 19-24 November (2000)

5. Villavicencio G. Méthodologie pour évaluer la stabilité des barrages de résidus miniers, Thèse de l'Université Blaise Pascal, Clermont-Ferrand (2009).

6. Chaigneau, L. Caractérisation des milieux granulaires de surface à l'aide d'un pénétromètre.
Thèse de l'Université Blaise Pascal, ClermontFerrand (2001).

7. Pournaghiazar, M., Russell, A. R. R. R. \& Khalili, N. 2011. Development of a new calibration chamber for conducting cone penetration tests in unsaturated soils. Canadian Geotechnical Journal, 48, 314-321.

8. Pournaghiazar, M., Russell, A. R. \& Khalili, N. 2013. The cone penetration test in unsaturated sands. Géotechnique, 63, 1209-1220.

9. International, A. 2003. Standart Test Method for Measurement of Soil Potential (Suction) Using Filter Paper. D5298-03 @ASTM International.

10. Muñoz-Castelblanco, J. A., Pereira, J.-M., Delage, P. \& Cui, Y.-J. Year. Suction measurements on a natural unsaturated soil: A reappraisal of the filter paper method. In: Unsaturated Soils - Proc. Fifth Int. Conf. on Unsaturated Soils, 2010-09-06 2010 Barcelona, Spain. CRC Press, 707-712.

11. Bicalho, K. V., Gomes Correia, A., Reis Ferreira, S., Fleureau, J.-M. \& Marinho, F. Year. Filter paper method of soil suction measurement. In: 13th Panamerican Conference on Soil Mechanics and Geotechnical Engineering, 2007-07-16 2007 Isla de Margarita, Venezuela.

12. M. Aubertin, M. Mbonimpa, B. Buissière and R.P. Chapuis, A model to predict the water retention curve from basic geotechnical properties, Canadian Geotechnical Journal, 40, 1104-1122 (2003). 